\title{
MÍDIA, SUBJETIVAÇÃO E CONSUMO DE NOTÍ́CIAS EM SITES DE REDES SOCIAIS
}

GABRIELA DA SILVA ZAGO 
MÍDIA, SUBJETIVAÇÃO E CONSUMO DE NOTÍCIAS EM SITES DE REDES SOCIAIS

Resumo: O trabalho promove uma discussão acerca do consumidor contemporâneo de notícias, a partir das relações que se estabelecem entre o sujeito e a mídia no contemporâneo. Toma-se como ponto de partida o processo de subjetivação, buscando relacionar com autores contemporâneos que discutem o papel da mídia na subjetivação. O consumo de notícias é discutido em especial a partir das particularidades de um canal específico: os sites de redes sociais. Palavras-chave: subjetivação; mídia; consumo; notícia; sites de redes sociais.

\section{MEDIOS DE COMUNICACIÓN, SUBJETIVIDAD Y CONSUMO DE NOTICIAS} EN SITIOS DE REDES SOCIALES

Resumen: El trabajo promueve una discusión sobre el consumidor contemporáneo de noticias, a partir de las relaciones que se establecen entre el sujeto y los medios de comunicación en la contemporaneidad. El proceso de subjetivación es tomado como punto de partida, tratando de relacionar a los autores contemporáneos que discuten el papel de los medios en la subjetividad. El consumo de noticias es tratado, en especial, a partir de las particularidades de un canal específico: los sitios de redes sociales.

Palabras clave: subjetividad; medios de comunicación; consumo; noticia; sitios de redes sociales.

MEDIA, SUBJECTIVITY AND NEWS CONSUMPTION IN SOCIAL NETWORK SITES

Abstract:The paper promotes a discussion on the contemporary news consumer, from the relationships that can be established between the subject and the media in the present-day. We take as a starting point the subjectivity process, aiming to relate to contemporary authors that discuss the role of media in subjectivity. News consumption is discussed especially from the particularities of a specific channel: social network sites.

Keywords: subjectivity; media; consumption; news; social network sites. 


\section{INTRODUÇÃO}

A subjetividade contemporânea é marcada pela cada vez mais forte presença da mídia na vida das pessoas. Se antes os meios exerciam o papel complementar de fornecer informações ao indivíduo, hoje eles se apresentam como elementos constituintes de nossa personalidade, sendo utilizados para obter informações, para entretenimento, e até para socialização, ao ponto de Deuze et al (2010) afirmarem que estaríamos vivendo uma "vida midiática". Ao invés de estar vivendo com a mídia, estaríamos, de fato, vivendo na mídia.

Com tantas modificações, a própria maneira como os indivíduos lidam com a informação se modifica. Cada vez mais o conteúdo informativo encontra-se misturado ao entretenimento - no que Gomes (2009) chama de infotainment e nem mesmo o espectador de televisão continua o mesmo - surge a figura do interator (MACHADO, 2011), um espectador ativo que não só assiste TV como também busca e compartilha conteúdos relacionados em outras mídias, como através da internet.

Diante desse cenário, como fica o jornalismo? Assim, buscamos, com este trabalho, apontar elementos que caracterizam o consumo contemporâneo de notícias, a partir das diferentes permeações possíveis entre mídia e subjetivação. Em um primeiro momento, apontamos aspectos da convergência de mídias, seguido de considerações acerca da relação entre mídia e subjetivação. Logo após são traçadas considerações sobre a sociedade de controle e sobre o consumo de notícias, e o trabalho encerra-se com uma discussão acerca do consumidor contemporâneo de notícias. Apesar de apresentar um panorama amplo, tentaremos, na medida do possível, focar a discussão no consumo de notícias através de sites de redes sociais.

\section{CONVERGÊNCIA DE MÍDIAS}

Se antes, para um telefone celular ter sucesso bastaria cumprir bem a função de fazer e receber ligações, atualmente os aparelhos combinam funções de envio de mensagens, acesso à Internet, câmera fotográfica, jogos, tocador de música e vídeo. Essa reunião de várias funções em um mesmo aparelho faz parte do contexto mais amplo de convergência tecnológica. Entretanto, conforme diz Jenkins (2008), a convergência não seria apenas um processo tec- 
MÍDIA, SUBJETIVAÇÃO E CONSUMO DE NOTÍCIAS EM SITES DE REDES SOCIAIS

nológico de reunir várias funções dentro de um mesmo dispositivo. "Em vez disso, a convergência representa uma transformação cultural, à medida que consumidores são incentivados a procurar novas informações e fazer conexões em meio a conteúdos midiáticos dispersos" (JENKINS, 2008, p. 27-28).

De fato, o termo convergência refere-se a diversos fenômenos simultaneamente. Além da convergência de funções, tem-se a convergência de linguagem, de interesses, de mídias, e também a convergência cultural. Para Jenkins (2008), a cultura participativa e a inteligência coletiva são elementos-chave para compreender a convergência das mídias em seu aspecto cultural. Essa possibilidade de colaboração e participação em rede contribui para o surgimento de fenômenos como conteúdos produzidos por consumidores.

A convergência midiática leva ao surgimento de novos arranjos midiáticos. Pereira (2008, p. 70) define arranjos midiáticos como "todo um conjunto de novos modos de diferentes mídias se associarem a outras mídias para efetivar práticas de comunicação". As combinações possíveis entre meios seriam tantas que analisar um meio específico, isoladamente, parece não dar conta das dinâmicas comunicacionais envolvidas (PEREIRA, 2008). Assim, para o autor, as mídias estariam a todo momento se combinando na forma de arranjos e ambientes midiáticos, que promovem novas experiências sensoriais e geram novas realidades.

Em um cenário de convergência midiática, também é importante destacar o papel dos meios. Para Santaella (2007), a palavra "mídia” é usada em excesso, ao ponto de descaracterizar seu conceito. Ainda que muitas vezes o termo seja usado para se referir a mídias de massa, a autora lembra que ele também pode se referir a outros níveis midiáticos e a outros tipos de mídias.

Para Shirky (2010, tradução nossa), "a mídia é o tecido conector da sociedade". É através dela que ficamos sabendo tanto de informações sobre o mundo quanto sobre o que está acontecendo com amigos próximos. De fato, a mídia estaria tão presente em nossas vidas que estaríamos vivendo não exatamente com a mídia, mas sim na mídia (DEUZE et al, 2010). Com isso, estaríamos experienciando uma vida midiática: “Antes de tudo, hoje temos que reconhecer o quanto os usos e as apropriações da mídia penetram todos os aspectos da vida contemporânea" (DEUZE et al, 2010, p. 1). Toda nossa experiência vivida perpassa a mídia. Nesse sentido, "não há mais um momento apartado para estar em contato com a mídia, já que estamos imersos nela, tornando a delimitação de barreiras algo complexo" (DRAMALI, 2010, p. 5) 
A presença das mídias seria tão intensa que muitas vezes elas se tornam invisíveis. Na maior parte do tempo, as pessoas esquecem que estão fazendo uso da mídia, "principalmente porque elas estão concorrentemente expostas a várias mídias ao mesmo tempo, e a maior parte de seu uso da mídia ocorre em combinação com outras atividades do dia-a-dia" (DEUZE et al, 2010, p. 2, tradução nossa). Exemplos de invisibilidade da mídia apresentados pelos autores incluem videogame sem controle e gigantescas TVs de plasma. Nesse sentido, as mídias seriam tão pervasivas e ubíquas que as pessoas já nem notam sua presença (DEUZE et al, 2010). Essa presença generalizada das mídias, muitas vezes combinada em diferentes arranjos e ambientes midiáticos, pode gerar mudanças significativas no modo como nos constituímos como sujeitos.

\section{MÍDIA E SUBJETIVAÇÃO}

Em termos gerais, subjetivação nada mais é do que o processo de tornar-se sujeito. Embora únicos enquanto entidade corpóreas, enquanto sujeitos somos um constante vir-a-ser. A todo momento somos subjetivados através de ações, pensamentos, e pelo modo como nos relacionamos com o que se encontra ao nosso redor. O processo de subjetivação no contemporâneo não é isento de conflitos: apesar de não ser a regra, há tentativas de resistência aqui e acolá. Isso acontece porque o processo é permeado por relações de poder. Para Foucault (1995), o poder depende de uma relação: trata-se de um modo de ação de alguns sobre outros. Por ser relacional, é exercido circunstancialmente. Ainda, para o autor, as relações de poder só se tornam possíveis entre sujeitos livres, na medida em que as formas de dominação reduzem as possibilidades de resistência.

Conforme Foucault (1995, p. 235), há dois significados para a palavra sujeito: "sujeito a alguém pelo controle e dependência, e preso à sua própria identidade por uma consciência ou autoconhecimento. Ambos sugerem uma forma de poder que subjuga e torna sujeito a". Em ambos os significados, está presente a ideia de uma relação permeada pelo poder.

Para Rolnik (1998), as subjetividades hoje seriam fluidas: "arrancadas do solo, elas tem o dom da ubiquidade - flutuam ao sabor das conexões mutáveis do desejo com fluxos de todos os lugares e todos os tempos, que transitam simultâneos pelas ondas eletrônicas". Além de fluida, a subjetividade é cada vez mais construída no tempo presente, no aqui e agora (SIBILIA, 2008). Para 
MÍDIA, SUBJETIVAÇÃO E CONSUMO DE NOTÍCIAS EM SITES DE REDES SOCIAIS

Sibilia (2008, p.125), estaríamos diante de um culto à vivência do instante, que decorre "[d]essa sensação de vivermos em um presente inflado, congelado, onipresente e constantemente presentificado" e ao mesmo tempo "conspira contra as tentativas de dar sentido à duração". O eu atual retoma o presente o tempo todo. No momento em que o indivíduo posta na web que fez algo, aquilo já se torna velho e obsoleto. Talvez por conta dessa velocidade exacerbada, temos como resultado "essa flagrante falta de sentido que flutua sobre muitas experiências subjetivas contemporâneas" (SIBILIA, 2008, p. 273). Ao mudar as formas e os tempos de se relacionar com o sistema midiático, mudam, também, os modos de consumo (IGARZA, 2010).

Em nossa sociedade atual, marcada pela onipresença da mídia, os dispositivos midiáticos exercem papel preponderante e constante em nossa definição enquanto sujeitos. Os efeitos da mídia no contemporâneo em nossos modos de ser e de se relacionar são inegáveis. Cada vez mais nossas interações passam a ser mediadas - pelo papel, pelo telefone, pelo computador, por e-mail, através de sites de relacionamento. Por estarmos cada vez mais imersos nesses meios, nossa existência acaba sendo permeada pela mídia. Somos aquilo que o meio nos permite ser. Somos aquilo que nossos perfis dizem que somos. 0 real e a representação do real se confundem no mesmo espaço. Apesar disso, oportunidades de resistência se mostram presentes (PEIXOTO JÚNIOR, 2008).

Do mesmo modo que outros meios como a televisão e o rádio, a internet é utilizada como meio tanto para informação como para entretenimento. Seu diferencial, porém, é poder ser usado também como ferramenta de trabalho e para o estabelecimento e a manutenção de relações sociais. Para Igarza (2010), a internet

é agora parte essencial de uma vida ociosa que se mescla alternando passagens de alta produtividade sem distinguir fronteiras horárias, sem aceitar a divisão tradicional entre o professional e o pessoal, o particular e o coletivo, o tempo de trabalho ou estudo e o de lazer. Ócio e produção já não são atividades que ocorrem de maneira dissociada, em lugares diferentes e tempos diferentes (IGARZA, 2010, p. 61, tradução nossa).

Essa nova relação dos sujeitos com os meios provoca modificações em diversos campos, incluindo o consumo midiático. 


\section{CONSUMO MIDIÁTICO E SOCIEDADE DO CONTROLE}

O século XX marca a passagem de uma sociedade disciplinar para uma sociedade de controle (DELEUZE, 2008). A sociedade disciplinar é marcada por moldagem social, por indivíduos que vão de uma instituição a outra, pelo fato de que sempre se "começa de novo", e pela materialidade (na forma de assinaturas, documentos). Já a sociedade de controle é marcada por protocolos e modulações, por indivíduos que transitam entre locais abertos, pelo fato de que nada está acabado, e por imaterialidades (senhas, computadores). "O controle é de curto prazo e de rotação rápida, mas também contínuo e ilimitado, ao passo que a disciplina era de longa duração, infinita e descontínua" (DELEUZE, 2008, p. 224).

Se na sociedade disciplinar a assinatura indica o indivíduo, e o número de matrícula indica sua posição numa massa, nas sociedades de controle o que se tem é uma cifra e uma senha. "A linguagem numérica do controle é feita de cifras, que marcam o acesso à informação, ou a rejeição" (DELEUZE, 2008, p. 222). As máquinas também mudam. Nas sociedades de soberania, que antecederam às sociedades disciplinares, as máquinas eram simples (como roldanas, alavancas e relógios). Nas sociedades disciplinares, as máquinas eram equipamentos energéticos. As sociedades de controle, por sua vez, "operam por máquinas de uma terceira espécie, máquinas de informática e computadores, cujo perigo passivo é a interferência, e, o ativo, a pirataria e a introdução de vírus" (DELEUZE, 2008, p. 223).

Às sociedades de controle corresponde uma forma política própria: o Império, "uma nova estrutura de comando, em tudo pós-moderna, descentralizada e desterritorializada, correspondente à fase atual do capitalismo globalizado" (PELBART, 2011, p. 81). O poder se exerce por redes flexíveis, moduláveis e flutuantes. Do mesmo modo, podemos dizer que há também uma forma típica de consumo de notícias em cada sociedade. Na sociedade disciplinar, marcada pela forte presença de instituições, o consumo de notícias é ligado a um determinado veículo ou meio, típico da mídia de massa. Poucos veículos exercem poder sobre muitos sujeitos. Na sociedade do controle, em que o poder encontra-se distribuído por todos e em todo lugar, uma nova forma de consumo emerge: fluido, a partir de diferentes canais e veículos, e essencialmente onli-

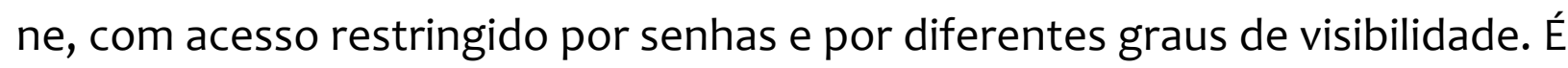


MÍDIA, SUBJETIVAÇÃO E CONSUMO DE NOTÍCIAS EM SITES DE REDES SOCIAIS

nesse contexto que procuramos inserir o consumo de notícias a partir de sites de redes sociais, um consumo fragmentado, baseado mais no conteúdo do que propriamente no meio ou veículo que fornece a informação.

\section{CONSUMO DE NOTÍCIAS}

O jornalismo pode ser entendido como um processo constituído de etapas: apuração, produção, circulação e consumo (MACHADO; PALACIOS, 2007). Nesse contexto, o consumo seria a última etapa do processo jornalístico, o momento em que o processo jornalístico se encerra. Após reunir material suficiente, contatar fontes e verificar informações (apuração), uma notícia é produzida e finalizada em formatos variados (produção), é posta em circulação nos diferentes suportes nos quais o jornal que a produz atua (circulação), e, partir do acesso a esses diferentes suportes, pode ser lida, vista, assistida, enfim, consumida (consumo). O consumo seria a perfectibilização do processo jornalístico, na medida em que envolve a leitura, e possivelmente a compreensão, do material produzido pelo jornalismo.

Atualmente, quase todos os jornais atuam em mais de um suporte (papel e online ou TV e online, por exemplo) (HEINRICH, 2011), o que complexifica a experiência de consumo de notícias, em parte pelo fato de que as notícias de um mesmo veículo podem estar disponíveis em diferentes meios. A partir da fusão e da aquisição entre diferentes grupos e veículos, surgem, também, verdadeiros conglomerados midiáticos. Mas longe de atuarem em uma ou outra mídia isoladamente, cada vez mais esses conglomerados procuram diversificar suas áreas de atuação.

Diante desse cenário, "Já é lugar comum dizer que, atualmente, as audiências estão se tornando crescentemente fragmentadas, dividindo seu tempo entre miríades de possibilidades de mídias, canais e plataformas" (MACHADO, 2011, p. 87). Com isso, estaríamos nos tornando verdadeiros onívoros digitais (COMSCORE, 2011), não só pelo tipo de conteúdo consumido, como também pelo acesso a diferentes plataformas. Com o consumo não mais definido exclusivamente pela plataforma em que ocorre, diferentes canais e possibilidades surgem para o indivíduo.

Um dos canais mais recentes para o consumo de notícias são os sites de redes sociais. Sites de redes sociais são espaços da web que permitem a criação 
e a manutenção de redes sociais (BOYD; ELLISON, 2007). Esses sites possuem finalidades variáveis, ainda que alguns elementos comuns sejam uma constante: construção de perfis representando indivíduos ou grupos, possibilidade de troca entre perfis e compartilhamento de mensagens a partir de um perfil para a rede como um todo. Como representantes típicos da sociedade de controle, a entrada nesses sites é mediada por uma senha de acesso. Mensagens de natureza variada podem ser compartilhadas entre os indivíduos em sites de redes sociais. Dentre essas inúmeras mensagens disputando atenção dos interagentes, podem-se encontrar notícias e links para notícias.

Os sites de redes sociais são aqui entendidos como híbridos entre plataformas de mídia e ambientes de sociabilidade (DRAMALI, 2010), na medida em que tanto podem ser utilizados para veicular informações, como para estabelecer conversações acerca de determinados assuntos. Isso traz implicações práticas para o jornalismo, na medida em que os jornais não são os únicos detentores exclusivos do poder de fazer circular uma notícia. A informação pode ser posta em circulação por interagentes, ao comentarem e linkarem notícias em seus perfis em sites de redes sociais.

Assim, o consumo de notícias nesses espaços pode se dar de diversas formas: pode-se acessar uma notícia a partir de um link compartilhado por um amigo, ou de uma manchete postada pelo perfil de um veículo no site de rede social. Pode-se aceder ao link diretamente na página inicial no site, ou encontrá-lo em alguma comunidade específica. Pode-se chegar ao acaso até o link, ou buscar especificamente por mais informações acerca de um determinado tópico.

Ao se receber recomendações de contatos, há menos importância da "marca” por trás da notícia (ou seja, qual veículo publicou uma notícia sobre aquele acontecimento), e um maior valor conferido à recomendação do amigo. Se antes o consumo estava vinculado a determinados meios e veículos (por exemplo, jornal impresso Folha de São Paulo, ou telejornal Jornal Nacional), hoje o consumo tende a ser mais fluido - ainda que, muitas vezes, a recomendação de um amigo seja acompanhada de uma fonte jornalística confiável que comprove a veracidade da informação repassada (RECUERO, 2011).

As redes socais têm se tornado espécies de serviços personalizados de notícias. Nos últimos anos, passou-se a consumir notícias cada vez mais a partir do 
MÍDIA, SUBJETIVAÇÃO E CONSUMO DE NOTÍCIAS EM SITES DE REDES SOCIAIS

que nos é repassado através da rede social de amigos (LAVRUSIK, 2010). Dessa forma, tem-se acesso a notícias personalizadas e customizadas para seus interesses, a partir de indicações de amigos. Receber notícias de pessoas em quem se confia em redes sociais é um tipo de filtro (LAVRUSIK, 2010).

O fato de que as pessoas estejam recorrendo cada vez mais às redes sociais em busca de informações talvez não seja a mudança mais significativa. Talvez a principal modificação esteja no fato de que a natureza do que é consumido também muda. Se antes o jornal impresso colocava à nossa disposição uma ampla gama de assuntos (ainda que muitos lessem apenas um ou outro caderno, os demais assuntos estavam ali, logo ao lado), o ambiente digital possibilita a hiperpersonalização (PELLANDA, 2007), o consumo apenas daquilo que interessa para as pessoas. Os dispositivos móveis potencializam esse consumo, na medida em que se tratam de ambientes de mídia always on, sempre conectado (PELLANDA, 2007). A personalização em excesso poderia levar à formação de filtros-bolha (PARISER, 2011), com sujeitos que consomem conteúdos cada vez mais personalizados para si e alheios ao que acontece no mundo fora de seu contexto particular e específico de interesse.

Diante de tamanha personalização, Pariser (2011) diz que estaríamos vivendo uma "sociedade Adderall". O Adderall é uma droga usada no tratamento do transtorno de déficit de atenção (TDAH). Um de seus efeitos é gerar uma atenção hiperfocada, fazendo com que um portador da doença, normalmente hiperativo, consiga se focar em uma determinada atividade. Para o autor, os filtros personalizados da internet poderiam ter o mesmo efeito em nossa capacidade de atenção, que ficaria voltada para determinadas temáticas e assuntos abordados por nossos pares, em detrimento de outras informações que não chegam até nós por estarmos presos a determinados filtros.

Essas especificidades do consumo midiático devem ser levadas em conta no estudo do consumo jornalístico, uma vez que informações jornalísticas passam a poder ser consumidas de formas diversas, a partir da apropriação do conteúdo feita por indivíduos que já consumiram previamente as informações e as filtraram para aqueles que acompanham suas atualizações em um blog, no Twitter ou em um site de rede social.

Nesse contexto, porém, notícias que apelam para emoção e entretenimento tendem a se destacar. Assim como na televisão, em que o infotainment, in- 
formação com entretenimento (ou entretenimento com informação) (GOMES, 2009) está cada vez mais presente, a presença de mensagens de humor é considerável ao se comentar notícias no Twitter (ZAGO, 2011)'.

Além disso, a tendência é que sejam compartilhadas notícias que despertem emoção ou surpresa (BERGER; MILKMAN, 2011). Notícias informativas puras praticamente não aparecem nos sites de redes sociais. Conforme pondera Boyd (2009),

Nossos corpos estão programados para consumir gordura e açucares porque eles são raros na natureza (...) Do mesmo modo, estamos biologicamente programados para prestar atenção em coisas que nos estimulam: conteúdo que é nojento, violento ou sexual e fofocas que são humilhantes, vergonhosas ou ofensivas. Se não tivermos cuidado, iremos desenvolver o equivalente psicológico da obesidade. Nos encontraremos consumindo conteúdos que são menos benéficos para nós mesmos e para a sociedade como um todo (BOYD, 2009, online, tradução nossa).

Assim, o consumo de notícias na internet, particularmente a partir dos sites de redes sociais, tende a ser fragmentado. Ao invés de ter acesso a todo tipo de conteúdo - como teríamos, em tese, ao ler um jornal impresso ou ao assistir um programa de telejornal - nosso acesso passa a ser restrito àquilo que nossos contatos postam em sites de redes sociais. Mais ainda: como os próprios sites de redes sociais possuem mecanismos internos para decidir o que é mostrado primeiro ${ }^{2}$, nossos filtros-bolhas acabam sendo ainda mais restritos.

Os próprios hábitos de compartilhamento de links e notícias entre os interagentes nos sites de redes sociais também influencia o tipo de conteúdo a ser consumido. A internet criou uma cultura de observação do outro e exposição de si próprio (SIBILIA, 2008). Estar na rede e não compartilhar é o mesmo que não estar na rede. $O$ incitamento ao compartilhamento seria tanto que Goldberg

1 Ao se analisar um total de 3.000 tweets sobre dois acontecimentos jornalísticos específicos, identificou-se que cerca de um terço das mensagens postadas por interagentes representava uma piada, paródia, ou outra forma de humor.

2 Por exemplo, no Facebook, a tecnologia que decide quais mensagens serão mostradas primeiro, EdgeRank, se baseia em três critérios: frequência de interações com o autor da atualização, tipo de conteúdo compartilhado e atualizações recentes (PARISER, 2011). 
MÍDIA, SUBJETIVAÇÃO E CONSUMO DE NOTÍCIAS EM SITES DE REDES SOCIAIS

(2011) afirma que estaríamos vivendo numa cultura da transmissão, e não da participação, na medida em que o valor de passar adiante uma informação, o mais rápido possível, torna-se mais importante do que a própria informação em si.

Na sociedade de hoje, de alguma forma, todos podem produzir conteúdo. Tudo pode ser interativo: "Os produtos e as experiências comercializadas sob a égide ou o manto da interatividade proliferam num desvario tão divertido quanto instrutivo" (FREIRE FILHO, 2007, p. 68). A própria televisão estaria em mutação, com audiências mais fragmentadas e espectadores mais envolvidos e menos passivos (MACHADO, 2011).

Com a possibilidade de compartilhar informações no mesmo espaço em que estas são consumidas, a fronteira entre consumo e produção se torna borrada (BRUNS, 2008; SANTAELLA, 2007) na medida em que mais e mais indivíduos passam a ter acesso aos meios de produção oferecidos pelas mídias digitais. "Em vez de falar sobre produtores e consumidores de mídia como ocupantes de papéis separados, podemos agora considerá-los como participantes interagindo de acordo com um novo conjunto de regras" (JENKINS, 2008: 28).

Domingo et al. (2007) consideram a audiência ativa como uma das dimensões da convergência jornalística. A audiência ativa tem a ver com o apagamento das fronteiras entre jornalistas e audiências, entre produtores e amadores (ANDERSON, 2006). Através desse processo, o jornalismo tem procurado incorporar as audiências não apenas no comentário de notícias como também na própria produção de notícias (DOMINGO et al, 2007), a partir da incorporação em formas de webjornalismo participativo.

Entretanto, conforme pondera Freire Filho (2007, p. 81)

Na maior parte dos casos, as formas de interatividade tecnológica que prometiam turvar ou dissolver a distinção entre produtor e consumidor, envolvendo as duas pontas do tradicional ciclo econômico num novo e afável exercício de co-autoria, acabam servindo, na prática, para transformar o usuário em funcionário (não-remunerado) das grandes corporações.

Assim, mais do que produsuários³ (BRUNS, 2008), muitas vezes os leitores

3 Tradução livre do termo produsers, neologismo proposto pelo autor a partir da junção dos termos produtores (producers) e usuários (users). 
fornecem conteúdos gratuitamente para os jornais, por intermédio de seções com títulos sugestivos como Leitor-Repórter ${ }^{4}$, Eu-repórter ${ }^{5}$ ou vc repórter ${ }^{6}$. O mesmo pode acontecer nos sites de redes sociais, em que os interagentes estão a toda hora diante de convites à participação, através de retweets, shares, likes e da utilização de determinadas hashtags, como formas de contribuir, ainda que indiretamente, para o processo jornalístico.

Para Pariser (2011), a relação entre identidade e mídia seria recíproca: como a identidade molda a mídia, a mídia molda o que vemos, o que cremos e com o que nos importamos (PARISER, 2011). Com isso, para o autor, ficaríamos presos a um looping de nós mesmos, na medida em que nossas escolhas ajudam a definir o que iremos consumir nos sites de redes sociais, ao passo que o que está disponível define o que consumiremos.

\section{CONCLUSÃO: O CONSUMIDOR CONTEMPORÂNEO DE NOTÍCIAS}

O trabalho procurou discutir o consumo de notícias diante da onipresença da mídia no contemporâneo, marcado pela sociedade de controle e por fronteiras cada vez mais difusas entre produção e consumo e entre meios. Diante de inúmeros meios e ofertas de conteúdo à disposição, os sites de redes sociais se apresentam como uma das opções de canais para se aceder a notícias. Nesses espaços, o conteúdo é filtrado por outros indivíduos, que acabam por promover um agenciamento coletivo do consumo de notícias.

O consumidor contemporâneo de notícias, assim, tende a possuir algumas características comuns: acessa conteúdos em múltiplas plataformas, recebe notícias e compartilha através de sites de redes sociais, é ativo e busca novas informações em outros espaços, quer consumir aquilo que aconteceu agora para poder compartilhar o quanto antes a informação. Como consequência desses fatores, está cada vez mais imerso em filtros-bolhas. Esses e outros elementos trazem implicações para sua constituição enquanto sujeito, que se constrói a partir de sua relação com a mídia e a partir daquilo que consome.

Há espaços para resistência - como ao criar um blog para escrever sobre

\footnotetext{
4 http://wp.clicrbs.com.br/doleitor/category/leitor-reporter/:topo=13,1,1,„,13

5 http://oglobo.globo.com/participe/

6 http://noticias.terra.com.br/vcreporter
} 
MÍDIA, SUBJETIVAÇÃO E CONSUMO DE NOTÍCIAS EM SITES DE REDES SOCIAIS

assuntos que não recebem destaque nos noticiários tradicionais, ou navegar a partir de caminhos não usuais através de sites de redes sociais (como a partir da busca por palavras-chave, por exemplo) - ainda que requeiram mais do que um consumidor de notícias ativo para que sejam acionados. Exigem, também, um consumidor consciente de notícias, que saiba que o fato de poder consumir e compartilhar notícias apenas sobre o que lhe interessa não o isenta de ir atrás de notícias sobre outros temas importantes que acontecem no mundo.

\section{REFERÊNCIAS}

BERGER, J.; MILKMAN, K.L. Social Transmission, and the Virality of Online Content. Journal of Marketing Research, 2011. Disponível em <http://marketing.wharton.upenn.edu/documents/research/virality.pdf>. Acesso em 23 dez. 2011.

BOYD, d. Streams of Content, Limited Attention: the flow of information through social media. In Web 2.0 Expo, New York, NY, 2009. Disponível em <http://www.danah.org/papers/ talks/Web2Expo.html> Acesso em 07 dez. 2011.

BOYD, d.; ELLISON, N. Social Network Sites: Definition, History, and Scholarship. Journal of Computer-Mediated Communication, 13 (1), 2007.

BRUNS, A. Blogs, Wikipedia, Second Life, and Beyond: From Production to Produsage. New York: Peter Lang, 2008.

COMSCORE. Digital Omnivores: how tablets, smartphones and connected devices are changing U.S. digital media consumption habits, 2011. Disponível em <http://www.comscore. com/por/Press_Events/Presentations_Whitepapers/2011/Digital_Omnivores >. Acesso em 23 dez.2011.

DELEUZE, G. Post-scriptum sobre as sociedades de controle. In: DELEUZE, G. Conversações. São Paulo: Ed. 34, 2008, p. 219-226.

DEUZE, M.; BLANK, P.; SPEERS, L. Media Life. Working paper, version 1.2, 2010. Disponível em <http://monitorando.files.wordpress.com/2010/08/vida-digital-mark-deuze.pdf $>$. Acesso em 27 ago. 2010.

DOMINGO, D. et al. Four Dimensions of Journalistic Convergence: A preliminary approach to current media trends at Spain. In: 8th International Symposium on Online Journalism, Universidade do Texas, 2007. Disponível em <http://online.journalism.utexas.edu/2007/papers/ Domingo.pdf $>$. Acesso em 10 jul. 2010.

DRAMALI, B. L. Internet: plataforma de mídia ou espaço de sociabilidade. Comtempo, 2(1), 2010. Disponível em <http://www.revistas.univerciencia.org/index.php/comtempo/article/ viewFile/6823/6473>. Acesso em 20 dez. 2011.

FOUCAULT, M. O sujeito e o poder. In: DREYFUS, H. \& RABINOW, P. (Orgs.). Michel Foucault, uma trajetória fislosófica: para além do estruturalismo e da hermenêutica. Rio de 
Janeiro: Forense Universitária, 1995, p.231-249.

FREIRE FILHO, J. Sociedade do espetáculo à sociedade da interatividade? In: GUTFREIND, C.F.; SILVA, J.M. (Orgs.), Guy Debord: antes e depois do espetáculo. Porto Alegre: EDIPUCRS, 2007, p.61-87.

GOLDBERG, G. Rethinking the public/virtual sphere: The problem with participation.

New Media Society, 13 (5), 2011, p.739-754, Disponível em <http://nms.sagepub.com/content/13/5/739>. Acesso em 10 set. 2011.

GOMES, I. M. M. O infotainment e a cultura televisiva. In: FREIRE FILHO, J. (Org.), A TV em transição. Porto Alegre: Sulina, 2009, p.195-221.

HEINRICH, A. Network Journalism. New York: Routledge, 2011.

IGARZA, R. Nuevas formas de consumo cultural: Por qué las redes sociales están ganando la batalla de las audiencias. Comunicação, Mídia e Consumo, 7 (20), 2010, p.59-90.

JENKINS, H. Cultura da Convergência. São Paulo: Aleph, 2008.

LAVRUSIK, V. How News Consumption is Shifting to the Personalized Social News Stream. Mashable, 2010. Disponível em <http://mashable.com/2010/08/10/personalized-news-stream/>. Acesso em 27 ago. 2010.

MACHADO, A. Fim da televisão? Revista Famecos, 18 (1), 86-97, 2011.

MACHADO, E.; PALACIOS, M. Um modelo híbrido de pesquisa: a metodologia aplicada pelo GJOL. In: LAGO, C.; BENETTI, M. (Orgs.). Metodogia de pesquisa em jornalismo. Petrópolis: Vozes, 2007, p.199-222.

PARISER, E. The Filter Bubble. New York: The Penguin Press, 2011.

PEIXOTO JUNIOR, C.A. Sobre a produção de subjetividade na atual sociedade do espetáculo. In: PEIXOTO JUNIOR, C.A. Singularidade e subjetivação. Rio de Janeiro: 7 Letras, 2008, p.187-202.

PELBART, P.P. Império e biopotência. In: PELBART, P.P. (Org.). Vida capital: ensaios de biopolítica (pp. 81-89). São Paulo: Iluminuras, 2011, p.81-89.

PELLANDA, E.C. Mobilidade e personalização como agentes centrais no acesso individual das mídias digitais. E-Compós, 2007. Disponível em http://www.compos.org.br/files/16ecompos09_EduardoPellanda.pdf. Acesso em 18 ago. 2010.

PEREIRA, V.A. G.A.M.E.S. 2.0. Gêneros e gramáticas de arranjos e ambientes midiáticos moduladores de experiências de entretenimento, sociabilidades e sensorialidades. In: ANTOUN, H. (Org.). Web 2.0: participação e vigilância na era da comunicação distribuída. Rio de Janeiro: Mauad X, 2008, p.65-82.

RECUERO, R. “Deu no Twitter, alguém confirma?" Funções do jornalismo na era das redes sociais. In: $9^{\circ}$ Encontro Nacional de Pesquisadores em Jornalismo, Rio de Janeiro, SBPJor, 2011. 
ROLNIK, S. Subjetividade Antropofágica. In: HERKENHOFF, P.; PEDROSA, A. (eds.). Arte Contemporânea Brasileira: Um e/entre Outro/s, XXIVa Bienal Internacional de São Paulo. São Paulo: Fundação Bienal de São Paulo, p. 128-147, 1998.

SANTAELLA, L. Linguagens líquidas na era da mobilidade. São Paulo: Paulus, 2007.

SHIRKY, C. Cognitive Surplus. Kindle Edition. Londres: Allen Lane, 2010.

SIBILIA, P. O show do eu. Rio de Janeiro: Nova Fronteira, 2008.

ZAGO, G. Recirculação jornalística no Twitter: filtro e comentário de notícias por interagentes como uma forma de potencialização da circulação. Dissertação (Mestrado em Comunicação e Informação), Porto Alegre, UFRGS, 2011.

RECEBIDO EM: 05/04/2013

ACEITO PARA PUBLICAÇÃO: 20/05

\section{Gabriela da Silva Zago}

Doutoranda e Mestre em Comunicação e Informação pela Universidade Federal do Rio Grande do Sul (PPGCOM/UFRGS). Professora do curso de Design Digital da Universidade Federal de Pelotas (UFPel). 